\title{
The importance of nutritional factors and dietary management of Hashimoto's thyroiditis
}

\author{
Paulina Ihnatowicz ${ }^{1, A-D, F \oplus}$, Małgorzata Drywieńn ${ }^{1, D-F} \oplus$, Paweł Wątor ${ }^{2, B-D \oplus}$, Joanna Wojsiat ${ }^{3, A, D-E} \oplus$ \\ ${ }^{1}$ University of Life Sciences, Warsaw, Poland \\ ${ }^{2}$ Agricultural University, Kraków, Poland \\ ${ }^{3}$ Nencki Institute of Experimental Biology PAN, Poland \\ A - Research concept and design, B - Collection and/or assembly of data, C - Data analysis and interpretation, \\ $D$ - Writing the article, $E$ - Critical revision of the article, $F$ - Final approval of article
}

Ihnatowicz P, Drywień M, Wątor P, Wojsiat J. The importance of nutritional factors and dietary management of Hashimoto's thyroiditis. Ann Agric Environ Med. 2020; 27(2): 184-193. doi: 10.26444/aaem/112331

\section{Abstract}

Hashimoto (HT) is an autoimmune disease in which destruction of the thyroid occurs as a result of lymphocyte infiltration. It is caused by an increased level of titers of antibody against thyroid peroxidase (TPO) and thyroglobulin (TG). Because of that,in HT patients, changes are observed in the level and metabolism of thyroid hormones, which leads to unspecified physical and psychological symptoms. A high level of antibodies attacking thyroid antigens has been positively correlated with the symptoms. From the etiological point of view, the most important are genetic factors; however, environmental factors are necessary to provoke the immune system to attack until the process is over. Scientists indicate specified stress, toxification, microbiota dysbiosis and under- or over-nutrition, to name only a few. Dietotherapy of Hashimoto's is based on the proper nourishment of the body and regulation of the immune system by an anti-inflammatory diet. Observational and controlled trials have shown frequent nutrition deficiencies in HT patients. In literature, there is evidence for selenium, potassium, iodine, copper, magnesium, zinc, iron, vitamin A, C, D and B. The role of the proper level of protein intake, dietary fibre and unsaturated fatty acids, especially the n-3 family, has been indicated. HT patients should often eliminate lactose because of intolerance and interactions with levothyroxine and gluten because of possible interactions of gliadin with thyroid antigens. The article describes the nutrition factors of HT patients, and share nutrition recommendations for diet therapy.

\section{- Key words}

hypothyroidism, lactose, gluten, diet therapy

\section{INTRODUCTION}

Hashimoto (HT) disease is one of the most frequently occurring autoimmune diseases, characterized by lymphocytic infiltration, destruction and scarring of thyroid tissue and the presence of antibodies to thyroid peroxidase and thyroglobulin [1]. The name "Hashimoto's disease" comes from the name of the Japanese surgeon Dr. Hakaru Hashimoto, who in 1912 described four cases of this disease. In a paper published in the Archiv für Klinische Chirurgie, Hashimoto presented the clinical and histological picture of the four cases, as he put it - 'the lymphocytic goiter, in which an intensive infiltrate of lymphocytes occurs with the formation of lymphoid follicles in the thyroid parenchyma' [2].

The disease is more likely to affect women than men, most often in women aged 30-60, and the risk of its development increases with age. However, what is important to note, is that this disease can be diagnosed in patients at any age, including children [3]. The frequency of Hashimoto's disease is a growing trend and among Caucasians it is estimated at approximately $5 \%$. Dysfunction of the gland may be clinically evident ( $0.1-2 \%$ of the population) or subclinical (10-15\%) [4]. The course of Hahsimoto's disease is related to impairment of the immune system, where an excessive production of antibodies against thyroid antigens occurs - thyroid peroxidase and thyroglobulin. The first protein catalyzes

Address for correspondence: Paulina Ihnatowicz, Warsaw University of Life Sciences, Poland

E-mail: dietetyk.innatowicz@gmail.com

Received: 10.05.2019; accepted: 07.08.2019; first published: 02.10.2019 the addition of iodine to tyrosine residues of thyroglobulin, from which triiodothyronine - containing 3 iodine atoms, or thyroxin - containing 4 iodine atoms is formed. Under normal physiological conditions, the level of antibodies is kept constant, while it increases in the disease. Their elevated level was positively correlated with the symptoms of Hashimoto's disease [5].

This article is based on an electronic search in PubMed and Google Scholar databases published from January 2009 - May 2019 regarding HT and use of the above-mentioned compounds as individual supplements or in combination with other on HT patients in clinical trials. The article focuses on the importance of nutritional factors for developing and progress of HT disease, and indicates which play a significant role in ethiopatogenesis of HT.

Factors connected with ethiopatogenesis of Hashimoto's disease. Hashimoto's disease is a disease of genetic, environmental and existential aetiology such as gender, parenthood and age. The genetic factors include major histocompatibility genes (encoding human leukocyte antigens), proteins regulating the immune system, and specific thyroid genes.

Genetic factors are the most significant in the development of autoimmune thyroid disease. Under the influence of environmental factors, they provoke the immune system to overproduce antibodies to thyroid antigens [6]. The environmental factors include, inter alia, an excess or a deficiency of nutrients, exposure to heavy metals, toxins, including endocrine disrupters, such as bisphenols, phthalates, drugs and others, [6, 7] (Fig. 1). 


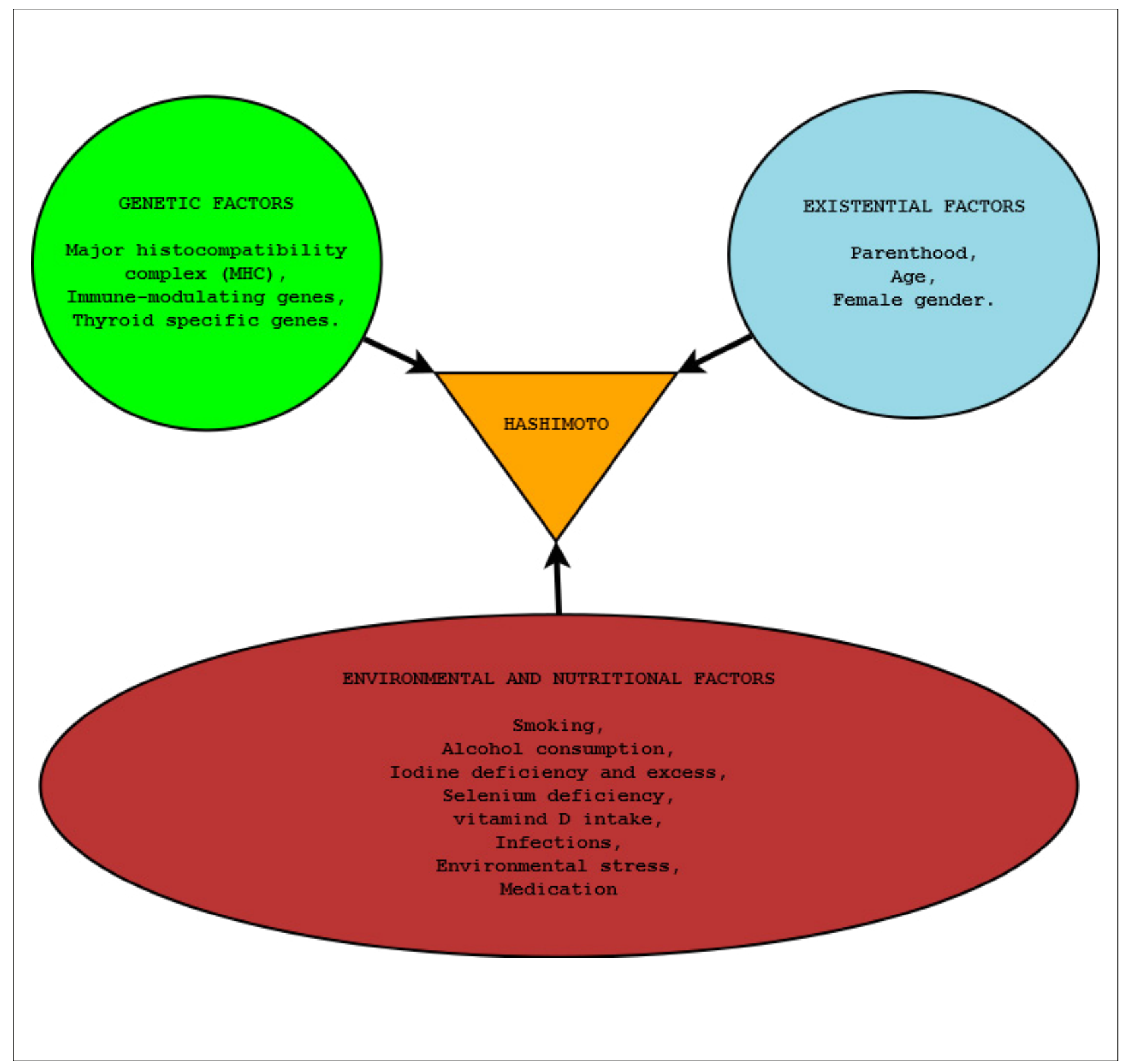

Figure 1. Environmental, genetic and existential factors in the immunopathogenesis of Hashimoto's disease.

Source: Own study based on $[6,9,10]$

The symptoms of Hashimoto's disease, as with other chronic diseases, initially are not acute and specific,. A few examples include change in mood, depression, concentration problems, brain fog, as well as biological changes: dry skin, hair loss, constant fatigue, even after getting enough sleep, changes in body weight or disturbances in bowel movements [8].

Molecular mimicry and infections. Infections are considered important factors in the etiopathogenesis of Hashimoto's disease which, as a result of molecular mimicry, i.e. geometric similarity or amino acid sequence of microbial antigens to human antigens, can cause a cross-reaction of the immune system and can lead to the development of autoimmune disease [11]. This is why immunoglobulins A play such an important role in the defence against infections which, together with the microbiota of the body, depend on a wellfunctioning intestine and a normal intestinal microbiota [12].
Stress. Mental health, often overlooked in this aspect, is significant in the development of Hashimoto's disease. Chronic stress significantly affects the physiology of the entire body. The mental state affects the physical state, which is assessed by the analysis of numerous biological markers. Chronic stress plays an important role also in the proper functioning of the immune system [13]; however, in contrast to Graves' disease, there is no research enabling such a conclusion in the case of Hashimoto's disease [6].

Oxidative stress. The causative factor behind the emergence of oxidative stress is free radicals. These are a group of oxygen and nitrogen compounds, which as a result of possessed unpaired electrons, are highly reactive and destructive molecules towards individual molecules, cellular structures, and consequently, the whole organism [14]. Their level in the body increases due to cigarettes smoking, alcohol consumption, ionizing radiation and excessive concentration 
of heavy metals (iron, copper, zinc) [15]. They are also caused by contaminants remaining in food, especially processed food, containing more glycation end products of nutrients [16], fluctuating blood glucose levels in postprandial time [17], postprandial lipaemia [18] or pathological conditions, like obesity [19].

Free radicals are also formed endogenously as a result of cellular processes carried out, where their main source are electrons escaping from the oxidative phosphorylation pathway $[14,20]$. Therefore, it is assumed that there is a relationship between mitochondrial dysfunction and the occurrence of chronic diseases. Although research on the relationship with Hashimoto's disease is still lacking, the study of thyroid cell transcriptome carried out by Cho et al. [21] shows that the changes arising from thyroid aging concern the reduction of gene expression associated with mitochondrial and proteasome functions - important in autophagocytic processes [22] - and increased production of proteins associated with autoimmune processes [21]. This is probably one of the reasons why the risk of Hashimoto's development increases with age.

Oxidative stress stimulates the release of inflammatory cytokines, which intensifies cellular destruction and ultimately can lead to programmed cell death - apoptosis [23]. The thyroid is an organ constantly affected by the oxidative stress phenomenon. This fact results from the continuous formation of hydrogen peroxide in the production of thyroid hormones [24]. Therefore, such an important role in thyroid protection is attributed to antioxidants, such as selenium $[25,26,27]$.

Studies on specific markers carried out in patients with Hashimoto's disease have shown an increased level of oxidative stress and damage resulting from it, compared to healthy people [26]. This indicates a lower antioxidant potential of the plasma and immune system of the patients compared to healthy subjects. A study conducted among 124 patients shows that this is indeed the case [28]. The level of glutathione, the most important antioxidant molecule of the immune system [29] was, as expected, also lower in patients compared to healthy people by even $60 \%$ [30]. In addition, the intensity of oxidative stress and the level of glutathione in the blood was correlated negatively with the level of antibodies against glutathione peroxidase, which suggests that the decrease in glutathione is a key factor for the emergence of oxidative stress and initiation of the autoimmune process [31]. It also places glutathione in the position of a possible therapy for lowering thyroid antibodies and silencing the autoimmune process [30]. The negative relationship was also found between the antioxidant potential of patients' blood plasma and the level of antibodies against thyroglobulin [32].

The mechanism of the relationship between oxidative stress and thyroid autoimmune is not well understood, although the over-production of free radicals, which lead to apoptosis, necrosis and thyroid function disorders, is now considered to be the main key [30]. Research to-date suggest that an adequately high level of glutathione $[30,33,34]$ plays both prophylactic and therapeutic roles in the mentioned processes.

Disturbance of the oxidation-reduction balance and the consequent oxidative stress itself, initiates autoimmune processes through destructive effects on the body's tissue structures which, as a result, may not be recognized by immune cells and may be attacked, which may lead to loss of tolerance to own tissues [35]. Especially in a genetically susceptible persons, oxidative stress bridges the initiation of autoimmune disease and environmental factors [26].

Oxidative stress is associated with the progression of Hashimoto's disease $[28,36]$, while in patients with improved thyroid function, a simultaneous improvement of the antioxidant potential was observed. Examining the impact of diet on changes in the oxidation and reduction potential of the body, expressed in the total number of peroxides in plasma, a relationship between the consumption of vegetables and fruit in the diet and the amount of oxidative damage measured in the blood was established. The increase in consumption of plant products was associated with a lower concentration of oxylipids in the blood and a decrease in the BMI index. The therapeutic significance of the reduction diet in patients with excessively developed body weight was also confirmed [37].

Nutritional factors. Due to the role of thyroid hormones in the regulation of metabolism, the resting metabolic rate in patients decreases with decreasing thyroid function, hence the possible accompanying increase in body weight resulting from excessive energy consumption. Due to the strong relationship between the developed adipose tissue and the intensity of oxidative stress, inflammatory and autoimmune processes [19] and the often occurring overweight or obesity in Hashimoto's disease [8], an important element of dietotherapy is the individually determined energy value. This should take into account the lifestyle and physical activity recommended to increase in the case of existing obesity, rather than to introduce energy restrictions.

An analysis of the diet of Polish patients with Hashimoto's disease showed that the average energy value of over $80 \%$ of menus checked daily was $1,600 \mathrm{kcal}( \pm 600 \mathrm{kcal})$, which was below the assumed value. Among the respondents, there were similar numbers of women with normal body weight and overweight and obesity, which allows the conclusion that, regardless of the body weight, the energy intake in this group could be inadequate. In addition, slightly higher than recommended consumption of protein and insufficient consumption of fat, including polyunsaturated fatty acids, especially omega-3 acids and dietary fibre, were observed, which was accompanied by excessive consumption of food products containing easily digestible carbohydrates [44]. This observation is logical, as with the processing of the food product, the fibre content decreases. The authors of the study found that the majority of patients required modification of the diet, and thus the support of a dietician. Those abnormalities are common among the general population, although it needs to be adjusted in the light of diet therapy.

It is worth paying attention to the potential interactions of drugs with food consumed with co-occurring diseases. They may affect the bioavailability of nutrients or affect the metabolism (e.g. cytochrome P450 activity) in a necessary way to be taken into account when creating a diet [38]. (Own translation of the quotation)

Hypothyroidism itself may cause disorders in the intestinal passage, leading to problems with defecation [8], hence attention should be paid to an adequate intake of water and fibre, which in Polish patients with Hashimoto's disease is too low [38]. In a study conducted among 60 Polish patients with existing constipation, the choice of a low-calorie diet $(-500 \mathrm{kcal})$ together with the use of barley 
dietary fibre supplementation in the amount of $30 \mathrm{~g}$, was conducive to weight loss, compared to the group free from supplementation. The fibre-taking group also reported less frequent voiding dysfunctions, although after 11 weeks of the study, these differences were not statistically significant [39]. Although supplementation with digestive fibre is a convenient therapeutic solution for some patients and incomparably worse than providing this nutrient from plant foods, in some cases it may be helpful. In the situation of insufficient consumption of plant food, and thus inadequate intake of dietary fibre $(<30 \mathrm{~g} / \mathrm{d})$ in the presence of overweight or obesity, requiring therapy, supplementation with soluble fibre may prove to support weight regulation. In case of problems with defecation, it can help but not necessarily [39], especially with an insufficient intake of fluids. The introduction of oat dietary fibre containing a lot of soluble beta-glucan fraction, however, would be helpful in influencing other metabolic parameters, such as: regulation of glucoseinsulin metabolism, plasma lipaemia, effect on intestinal microbiota, immunomodulatory, and other effects [40] which are disturbed in Hashimoto's disease [8].

In the study of patients with Hashimoto's disease with a thyroid-stimulating hormone (TSH) level between $0.4-$ $4.5 \mathrm{mU} / \mathrm{L}$, not taking medication, after dividing them into groups with lower $(0.3-2.5 \mathrm{mU} / \mathrm{L})$ and higher $(2.5-4.5 \mathrm{mU} / \mathrm{L})$ levels, it was apparent that patients in the group with increased TSH in the blood also had a 1.7 times greater risk of developing metabolic syndrome [44]. This indicates the need for prophylaxis of the cardiovascular system in patients with high levels of TSH in the blood, the more so that they may also have an elevated level of triglycerides in the blood [44, 41].

The immune-mediated disease requires a diet with a focus on supporting the immune system towards regulating inflammatory processes by meals in terms of their composition and method of preparation, as well as elimination of problematic food antigens. In addition, attention should be paid to the intake of energy, vitamins and minerals used in thyroid metabolism, and as defence elements of the immune system against oxidative stress, and their deficiencies are closely related to the condition of the organ, and thus the whole organism. Among patients suffering from autoimmune thyroid disease, there is a deficiency of such minerals as: iodine, iron, zinc, copper, magnesium, potassium and vitamins A, C, D and B group vitamins [8]

Protein. One of the assumptions of the therapeutic diet is a sufficiently high intake of protein, meeting the daily requirement in the state of the disease. In the case of Hashimoto's disease, increasing the intake of whole meal protein from unprocessed products (meat, sea fish, especially fatty fish, eggs) can be helpful in reducing the excessively developed body weight. Due to the possible need to eliminate milk and dairy products, they might not be a source of protein in Hashimoto's disease, although vegetable substitutes like coconut, almond or rice milk also contain protein [42].

Co-occurring along with insufficient energy intake, protein malnutrition intensifies iodine deficiency and thyroid gland damage, although these changes are mainly observed in malnourished children. However, in patients with Hashimoto's disease with caloric-protein malnutrition, elevated levels of TSH may be more frequent than in wellfed patients, which results from the body's natural adaptive response to protein and energy deficiency [8].
Iron. Iron deficiency is often co-occurring Hashimoto's disease [43] and is a frequent consequence is anaemia which, although it does not result from the disease itself, is most often caused by co-occurring celiac disease, leading to malabsorption of other minerals, not only iron [8]. Iron is necessary in the production of thyroid hormones, and its deficiency blocks the activity of thyroid peroxidase, for which iron is necessary. As a result, a reduction in the synthesis of thyroid hormones is observed, as well as increase in TSH level and gland volume. Anaemia may therefore increase the risk of developing thyroid disease [44], and the improvement of iron intake in the case of its deficiency improves the functioning of the thyroid [8].

Iodine. Iodine is a component necessary for the functioning of the entire organism, including proper functioning of the thyroid, and in pregnant women for the development of the nervous system in the foetus [8]. This increases the iodine demand in this group of women by 30\% [45]. The iodine salt fortification applied in Poland improved nutritional status and decreased iodine deficiency, including in pregnant women. Pregnant women should consume $250 \mu \mathrm{g}$ of iodine per day, while children over 12 years of age and adults $-150 \mu \mathrm{g}$, as recommended by the World Health Organization [46].

In Poland, iodine fortified salt is one of the sources of iodine, although there are states in which it is necessary to reduce its consumption. Then, the increase is recommended of the consumption of seafood [47], as well as drinking mineral waters, such as: Wysowianka, Kujawianka, Muszynianka, Piwniczanka, Szczawianka and Celestynka, which contain 0.1-0.2 mg of iodides per litre of water, which makes them a good source of iodine [48], as well as other minerals, including calcium and magnesium [49].

Iodine deficiency is a known factor causing thyroid goiter, but its excessive intake [50], even in excess of $1 \mathrm{mg}$ per day, may lead to weakening of the thyroid function and occurrence of the Wolff- Chaikoff effect. This effect defines the phenomenon of decrease in thyroid function in response to absorption of a higher amount of iodine after its intake, and then return to normal synthesis of thyroxine and triiodothyronine over several days. The problem is that in some patients, the thyroid does not return to normal hormone production and a persistent hypothyroidism develops [51]. In other words, taking iodine in the form of a supplement in amounts over several hundred $\mu \mathrm{g}$ and higher may lead to hypothyroidism.

So what dose of iodine is safe? A study conducted by Sang et al. [51] shows that subclinical hypothyroidism, measured by the volume of the organ and the level of TSH in the blood, has already developed in some subjects using $400 \mu \mathrm{g}$ of iodine supplement and total iodine intake of $800 \mu \mathrm{g}$ per day. This indicates the lack of a safe upper limit of iodine intake, as it is highly individual.

Too much iodine is toxic to cells, it can cause damage and initiate apoptosis or necrosis. This is due to the possible oxidation effect of iodine, so as oxidative stress, it may lead to progressive destruction and tissue atrophy. In in vitro studies on cells taken from patients with Hashimoto's disease, an excessive amount of iodine led to suppression of autophagocytic processes, stimulation of apoptotic processes and increase in the production of free radicals [52]. 
Iodine and selenium. The lack of consistency in the results of the tests regarding the effectiveness of iodine therapy, as well as the differences in thyroid health depending on the consumption of iodine, indicate an additional nutrient factor, i.e. the selenium intake.

One of the toxic effects of excess iodine is the blockade of enzymes with selenocysteine residues, i.e. glutathione and thyroid peroxidases, which leads to a decrease in their activity, thus, besides a possible prooxidative effect iodine can also inhibit the activity of antioxidant enzymes. It turns out that this process can be stopped. In rats, which were given selenium along with an excess of iodine, no thyroid pathology was observed [53]. It was also found that selenium reversed the changes caused by the iodine given in excess. Mice developed autoimmune hypothyroidism by consuming iodine for 8 weeks. After this time, selenium was added and the test continued for a further 8 weeks. The thyroid mass of mice receiving iodine alone after 8 weeks was twice as high as in the control group, although it returned to normal after another 8 weeks of supplementation with iodine and selenium at the same time. It is worth noting that the anti-thyroglobulin antibodies raised in the iodine group also returned to the level equal to the control group after selenium intake. Changes were also observed in immune system regulatory cells, the number of which decreased in the state of excessive iodine supply. This favoured the development of autoimmune processes, which were regressed to the initial level after selenium intake. Proper selenium intake may protect against the adverse effects of iodine [54].

Data collected from studies in humans show that selenium concentration in blood below $60 \mu \mathrm{g} / \mathrm{L}$ and above $140 \mu \mathrm{g} / \mathrm{L}$ increases the risk of diseases caused by deficiency (e.g. autoimmune diseases, including Hashimoto's thyroiditis, cancer) or excess selenium (e.g. hyperlipidaemia, type 2 diabetes) [55] whereas the appropriate nutrition $(60-140 \mu \mathrm{g} / \mathrm{L})$ is necessary for health and may inhibit the toxic effect of excessive iodine [27].

The excessive and toxic effects of iodine lead to thyroid damage and stimulation of autoimmune processes, which is inhibited by proper selenium nutrition. In the state of selenium deficiency, the thyroid is susceptible to the effect of iodine, which is indeed necessary, but harmful without the presence of selenium. Selenium stimulates the activity of regulatory cells to block the release of interleukin (IL)-2, which stimulates autoreactive T-cells and B-lymphocytes to produce antibodies against the thyroid [27]. It is worth pointing to the reports on the role of selenium in blocking the secretion of inflammatory cytokines by T lymphocytes [56].

Epidemiological studies conducted in Poland [57] have indicated the occurrence of selenium deficiencies in patients with Hashimoto's disease compared to healthy people. Unfortunately, it was not found that eating habits had a significant influence on the concentration of selenium in the blood. These results suggest insufficient selenium intake in Poland.

The content of selenium in food products is varied. There is a lot of it in yeast. However, in everyday products, it is contained mainly in combination with proteins, hence, meat, fish, animal offal and unprocessed cereal products are a good source of selenium. Cereal products along with dairy products contain slightly smaller amounts, although they are still a better source than vegetables and fruit, containing a small amount of protein and high amount of water, and therefore little selenium. Among plant products, it is worth paying attention to popular mushroom Agaricus, a source of selenium [58], glutathione [59] and vitamin D, which is often lacking in patients suffering from Hashimoto's thyroiditis [60]. Oily fish and seafood are also recommended [47].

Zinc. Zinc is involved in the production of thyroid hormones, and its deficiency leads to disturbances in their level and to the increase in antibody titers against thyroid antigens. Improvement of the nutritional status of this mineral in patients with Hashimoto's disease restores normal thyroid function caused by its deficiency $[8,42]$. A characteristic feature of zinc deficiency in hypothyroidism may be hair loss, which will be inhibited by improving zinc nutrition [61].

Among the products containing the largest amounts of zinc there are pumpkin seeds, flax seeds, whole grain cereals, such as wholemeal bread, millet and buckwheat. Most Poles provide zinc with cereal products, and to a lesser extent with meat and meat preparations [47].

Magnesium. Magnesium is one of several minerals, deficiencies of which are most common in the world. As a result of its extensive participation in human metabolism, including participation in the functions of several hundred enzyme proteins, magnesium deficiency is correlated with a higher risk of many diseases and their progression. As far as the immune system is concerned, magnesium has anti-inflammatory activity, including reducing the level of reactive $\mathrm{C}$ protein and the level of antibodies against thyroglobulin. A strong magnesium deficiency increases the risk of developing Hashimoto's disease, and in patients it may exacerbate the symptoms of the disease as a result of disorders of the immune system [62].

Vitamin D. Vitamin D in the human body comes from 2 sources: endogenous, which is the skin, where the vitamin is formed in the presence of sunlight, and exogenous, which is food. Rich sources of vitamin D are oily fish (sardines, salmon, cod) and mushrooms, especially when sun-dried [60].

Research indicates the presence of vitamin $\mathrm{D}$ deficiency in the blood in patients with autoimmune diseases $[9,63]$ in all age groups in whom antibody titers and thyroid function improve with the improvement of cholecalciferol nutrition $[60,64]$. Biologically active $1,25-(\mathrm{OH}) 2 \mathrm{D} 3$ bound to special receptors penetrates to the cell nucleus where it gives rise to a final complex with retinoic acid, which interacts with vitamin $D$ responsible elements in the promotor region of the regulated gene [65]. The final effect is an activation or suppression of as many as 200-500 genes, representing about $3 \%$ of the human genome [65]. With respect to the topics of this paper, the most important are the genes, ensuringthe physiological function of the immune system. Experimental studies have proved the direct protective effect of 1,25-(OH)2D3 in combination with suppression of an autoimmune inflammation, along with influencing of T-lymphocytes and an impact on antigen presenting cells, especially dendritic cells [65]. Patients with Hashimoto's disease, compared to healthy people, may have even a twice-lower level of vitamin $\mathrm{D}$ in the blood, which may result from different eating habits or the occurrence of the disease itself $[60,64]$. Hence, the need to educate the population in this respect, the more so that the increase of vitamin $\mathrm{D}$ in the blood by $5 \mathrm{ng} / \mathrm{mL}$ is associated with a 
$19 \%$ reduction of the risk of developing hypothyroidism in lymphocytic thyroiditis [67].

Microbiota and inflammatory processes. The intestines contain the largest amount of tissue and cells of the immune system that are in close contact with the intestinal microbiota. The state of microbiota in adults is fairly stable, although it adapts constantly to eating habits and changes during illness. In patients with Hashimoto, microbiota dysbiosis is observed, which stimulates autoimmune processes [10]. The occurrence of individual bacterial strains in Lymphocytic Thyroiditis dysbiosis with clinical indicators of the disease was related. [68].

Fluctuation of thyroid hormone levels themselves can affect the composition of intestinal microbiota and its amount, and patients with Hashimoto's thyroiditis have a higher risk of developing intestine bacterial overgrowth. This works mutually because microbial disorders also lead to changes in metabolism, because they participate in the circulation and deconjugation of thyroid hormones. Animal studies have demonstrated that some bacterial strains Lactobacillus and Bifidobacterium, also part of the human commensal microbiota, depend on the concentration of thyroid hormones and its function [10].

Lactulose and mannitol tests showed an increased intestinal permeability in patients with Hashimoto's thyroiditis, compared to the control group [10], which together with the fact of increased expression and activation of Toll-like receptors in mononuclear peripheral blood cells in patients with lymphocytic thyroiditis, points to the relationship between the state of microbiota and inflammatory processes and thyroid function [69]. It was shown that the specific inflammatory marker IL- $1 \beta$ stimulates the secretion of inflammatory cytokines from thyrocytes mediated by the MPAK/NF-kB pathway, therefore under conditions of chronic inflammation, thyroid secreted cytokines may increase the lymphocytic infiltration of its own tissue [70]. Improvement of intestinal microbiota is necessary to reduce the intensity of inflammatory processes in the body stimulating autoimmune processes [71].

In order to improve the quality of microbiota, patients should consume the right amount of vegetables and fruit [72]. Attention should also be paid to:

- type of fat consumed; excessive intake of saturated fatty acids can lead to changes in the microbiota in a direction conducive to the leaky intestinal syndrome, and molecular patterns associated with pathogens. In contrast, the intake of polyunsaturated fatty acids promotes the quality of microbiota and the improvement of metabolic functions $[73,74]$;

- choosing products with a lower degree of processing from among those possible. Whole grain products contain more dietary fibre in a mass unit, compared to refined products. Consumption of wholegrain foods is associated with a more beneficial composition of microbiota [72];

- increasing the consumption of foods rich in secondary plant metabolites, including phenolic compounds. They modulate the composition of intestinal microbiota or support the balance in the state of dysbiosis [72]. These are: cocoa [75], honey $[76,77]$ fruits and vegetables;

- the amount of omega-3 fatty acids consumed in the diet, due to their relation with the intestinal microbiota, immunomodulatory and anti-inflammatory effects [78].
Consumption of oily fish is recommended twice a week. Omega-3 acids in the amount of $\sim 1-2 \mathrm{~g}$ should be provided daily. Food containing them is definitely a better choice than supplementation in the form of capsules [79], which should be introduced only when recommended by a medical professional;

- in patients with Lymphocytic Thyroiditis it may be necessary to analyze the composition of intestinal microbiota and the possible use of pre-, pro- or symbiotic, as well as the condition of the intestinal wall with respect to possible increased intestinal permeability with respect to healthy people [80];

- consumption of a minimum of $25 \mathrm{~g}$ of dietary fiber. Undernourished intestinal bacteria lead to changes in the functioning of the immune system, including stimulation of autoimmune processes, and reduced expression of proteins associated with intestinal permeability is observed [81].

\section{ELIMINATION NUTRITION IN HASHIMOTO}

Elimination of lactose. A diet targeting the treatment of Hashimoto's disease often requires elimination of dairy products containing lactose. Lactose intolerance is diagnosed in $75.9 \%$ of the patients with HT [82]. This intervention is all the more important in people taking levothyroxine, as lactose intolerance reduces the bioavailability of the drug and enforces the use of higher doses, hence the patients taking it or patients with elevated TSH should perform a lactose tolerance test and eliminate it if necessary [83].

Elimination of gluten. Gluten is a particularly interesting factor because of its association with autoimmune diseases, including Hashimoto. The reasons for this are seen in the occurring cross-reactions between gliadin and thyroid antigens [84]. Gluten is the ingredient most often required to be eliminated from the diet of lymphocytic thyroiditis patients due to the coexistence of other autoimmune diseases with which gluten intake is associated, including coeliac disease and non- coeliac gluten intolerance. Coeliac disease among Hashimoto's thyroiditis patients occurs from several to 10 times more often than in the healthy population [85-86]. For this reason, if coeliac disease is suspected, a diagnostic test should be carried out under the direction of a physician before the gluten-free diet is applied to avoid false test results. An implicit form of coeliac disease should be kept in mind, which may be the cause of nutritional deficiencies and disorders in the absorption of medicines. For this reason, Hashimoto's thyroiditis patients without symptoms, but with the problems of achieving adequate nutrition and regulation of thyroid hormones, should be prophylactically examined for coeliac disease [84]. Furthermore people with coeliac disease should be diagnosed in terms of Hashimoto's thyroiditis, or at least observe this, because of the cross-reaction of the immune system and the possibility of simultaneous attack on both of these tissues [87]. This is due to the molecular mimicry leading to the cross-reactivity of the immune system where antibodies directed against food antigens have structural similarity to the structures of the body's tissues. Thus, specific food products, by activating the immune system, can lead to exacerbation of the disease or its initiation because in people with positive antibodies to food antigens more than twice as often the positive antibody result against the tissues of their 
own body is observed [87]. However, these dependencies and therapeutic significance require further research [88].

Nevertheless, one should bear in mind the positive effect of elimination of potentially harmful products in Hashimoto's thyroiditis patients, especially gluten. Patients with latex and fruit allergy associated with latex-fruity syndrome, such as bananas, kiwi, avocado, peach, potatoes and tomatoes, edible chestnuts, and less likely to cause cross reactions: melon, mango, pineapple [89], should direct attention to their consumption due to the possibility of cross-reactivity with thyroglobulin [88].

Research on over 200 different food products carried out by Kharraziana et al. [88] showed cross-reactions of several dozen with thyroid hormones. Buckwheat was the only one of the products to cross-react with type II deiodinase, which may suggest that buckwheat affects the conversion of thyroid hormones. Dozens of products cross-reacted with thyroid hormones, among them cereals containing gluten, and products with amino an acid sequence compatible with triiodothyronine and/or thyroxine, such as seaweed, potatoes, nuts (almonds, cashews, hazelnut, peanut, Brazilian nut), seafood, amaranth, buckwheat, coffee, corn, egg yolks, quinoa, sorghum, tapioca and tofu, among others [88].

The results of this study do not mean that these products cause or can cause reactions in Hashimoto's thyroiditis patients. There is a lack of data in this area to scientifically support such a statement, the more so because the pathological reaction results, not only from the antigenantibody interaction, but dependent on other factors, including genetic factors. This suggests only possible crossreactions in Hashimoto's thyroiditis patients, and in the case of ineffective dietary therapy, it is worth taking this into account [88].

The use of a gluten-free diet should be supported by a dietician in order to avoid potential nutritional deficiencies found in the areas of iron, calcium, zinc, manganese, selenium, vitamin $\mathrm{D}, \mathrm{B}_{12}$ and folate, magnesium [90]. Deficiency of these minerals in the general population is not surprising. All these components are necessary for the proper functioning of the immune system and thyroid.

In the previous year, Polish scientists published results of a study [1] in which participated 34 women aged 20-45, with newly-diagnosed Hashimoto's thyroiditis and the presence of anti-tissue transglutaminase antibodies without clinical symptoms of coeliac disease. The subjects had not previously adopted a gluten-free diet. In group A $(n=16)$ an exclusion diet was adopted for 6 months, while group B $(n=18)$ remained as a control group. During the study period and at the end of the study, no one developed coeliac disease. After completion of the study, antibodies were observed in 6 out of $16(38 \%)$ patients in the exclusion group, while 18 out of $18(100 \%)$ were observed in the second group. Positive changes were also observed in the level of antibodies, thyroid hormones and vitamin D (Tab. 1).

The 6-month period of application of the exclusion diet led to a significant reduction in the level of antibodies directed to thyroid peroxidase (Anti-TPO) and thyroglobulin (Anti$\mathrm{TG}$ ), and a small increase in the level of vitamin $\mathrm{D}_{3}$ in the blood. The level of free hormones did not change significantly in either group. Interestingly, in group A, thyroid secretory functions improved which, together with the decrease in the level of antithyroid antibodies, was associated with a decrease in antibodies to transglutaminase.
Table 1. Effect of the gluten elimination diet in women with newlydiagnosed Hashimoto's thyroiditis and anti-tissue transglutaminase antibodies on the level of antibodies to thyroid antigens and vitamin D levels in the blood. The indicated values show the differences between those collected at the beginning of the study and after its completion [1]

\begin{tabular}{lccc}
\hline Marker & $\begin{array}{c}\text { Group A gluten-free } \\
(n=16)\end{array}$ & $\begin{array}{c}\text { Group B free of intervention } \\
(n=18)\end{array}$ & Difference \\
\hline Anti-TPO [U/mL] & -200 & 29 & 229 \\
\hline Anti-TG [U/mL] & -203 & 53 & 256 \\
\hline FT4 [pmol/L] & 1,2 & 0,3 & $-0,9$ \\
\hline FT3 [pmol/L] & 0,4 & 0,1 & $-0,3$ \\
\hline $25, \mathrm{OHD}[\mathrm{ng} / \mathrm{mL}]$ & 5 & -1 & -6 \\
\hline
\end{tabular}

Curiously enough, the authors point to the clear advantage of adopting the exclusion diet for the level of vitamin $\mathrm{D}_{3}$ in the blood. In group $\mathrm{A}$, it increased by $5 \mathrm{ng} / \mathrm{mL}$, which according to Mansournia et al. [67], reduces the probability of developing Hashimoto's disease by $19 \%$, while in group B only by $1 \%$. Initial values in group A and B were successively $20 \mathrm{ng} / \mathrm{mL}$ and $21 \mathrm{ng} / \mathrm{mL}$, thus even an increase to $25 \mathrm{ng} / \mathrm{mL}$ left all subjects in a state of malnutrition. This is consistent with other publications indicating frequent deficiencies of vitamin D in Hashimoto's thyroiditis patients [60, $63,64]$, including Polish patients $[9,66]$. It is not known what was responsible for the increase in the key vitamin in the blood, although it remained well below the desired level $[9,60]$. As it is the only one pilot study suggesting the beneficial effect of a gluten-free diet in the course of Hashimoto's disease, further investigation is needed before any recommendations regardingthe exclusion diet. So far, there are no recommendations for gluten elimination in Hashimoto's diet therapy. Moreover, the Expert Committee of the Section of Medical Dietetics of the Polish Society for Parenteral, Enteral Nutrition and Metabolism (POLSPEN), undertook a review of the article about a gluten-free diet in Hashimoto's thyroiditis. According to POLSPEN, following the gluten-free diet by Hashimoto's thyroiditis patients is justified only in the case of coexistence with coeliac disease [91]. Moreover, a gluten-free diet should not be encouraged in Hashimoto's disease without co-occurring coeliac disease or another form of gluten intolerance [91]. Besides, longterm following an improperly balanced gluten-free diet may be potentially harmful, due to many adverse health effects including increased cardiovascular risk.

Nutritional tips to balance diet in HT. On the basis of the above data and recommendations from Polish scientific journals for patients with Hashimoto's disease [42, 84], the recommendations are as follows:

- regular consumption of 4-5 meals daily which provide nutrients, the deficits of which are observed in patients:

- vitamin D: fatty fish, fish oil, sun-dried mushrooms, Agaricus (and solar bath), chicken eggs;

- B group vitamins: meat, fish, chicken eggs, wholegrain cereal products;

- vitamin A: kale, carrot, pumpkin, liver, spinach, egg yolk, butter, dried apricot;

vitamin C: (although not a rich source, it raises the level in blood), black currant, kiwi, strawberry, orange, mango, lemon, melon, kale, spinach, tomatoes, peppers (especially red peppers); vegetables and fruit are basically the main sources; 
- vitamin E: avocado, fish oil, whole-grain cereal products, vegetable oils;

magnesium: cocoa and bitter chocolate, pumpkin seeds, avocado, nuts, whole grain cereal products, some fatty fish (salmon) and green vegetables, yogurt, kefir;

zinc: cocoa and bitter chocolate, meat, kefir, yogurt, pumpkin seeds, nuts, spinach, mushrooms, whole-grain cereals;

- iron: meat, animal offal, cocoa and bitter chocolate, spinach, sardines, seafood, pumpkin seeds;

iodine: iodized salt, fish (cod, tuna) and seafood as well as seaweed, iodized milk and dairy products, if elimination is not required, chicken eggs, plum, especially dried plums, maize;

- selenium: Brazilian walnut, fish (sardines, halibut, salmon, tuna), meat, spinach, liver.

- Adjusting the energy value to the individual needs of the patient, as the caloric restriction or low-fat diet may affect the thyroid function.

- Preferable sources of fats are: olive oil, avocado oil, avocado, rapeseed oil, walnut oil or walnuts, oily fish and seafood.

- Increasing the supply of protein from the recommended $10-15 \%$ total dietary energy intake to $15-20 \%$ n or even $25 \%$, recommended total dietary energy intake. Oily fish, chicken eggs from organic farming and organic cow meat is good sources of both protein, iodine, iron, zinc and omega-3 acids.

- Providing carbohydrates from whole grains; characterized by a higher nutritional density and dietary fibre.

- Increasing the intake of soluble fibre supports intestinal microbiota and can improve defecation and bowel function, which is a common problem in hypothyroidism. Plantbased food, such as cocoa, fruit and vegetables, as well as whole-grain cereal products, are good sources of fibre.

- Taking care of nourishing the microbiota by eating vegetables and fruit, dietary fibre and silage products.

- Limiting the consumption of processed products, including sweets, chilled beverages and other sources of sucrose or simple sugars.

- Eliminating gluten is not recommended if coeliac disease or other forms of gluten intolerance are not present.

- Adopting a diet that eliminates food allergens when food allergy is diagnosed.

\section{CONCLUSIONS}

Hashimoto's disease is closely related to genetic predispositions, which under the influence of environmental factors, lead to stimulation of the immune system's activity, loss of own tolerance and development of the autoimmune process. Dietary factors can be considered as part of the environmental factors, which are within reach and the possibility of modifying each patient, which - as results from the nutrition analysis of Hashimoto's thyroiditis patients - is insufficient and requires analysis and the support of a dietitian.

In the Hashimoto diet therapy, one should take into account the co-occurrence of other diseases, including those that may contribute to malnutrition with nutrients (coeliac disease, inflammatory bowel diseases). In the case of Hashimoto's disease, an inadequate intake or malnutrition with the following nutrients can be observed: iron, zinc, magnesium, selenium, excessive or insufficient intake of iodine, vitamin $A$, vitamin $\mathrm{D}$, antioxidant vitamins and $\mathrm{B}$ group vitamins, as well as the appropriate quality and amount of omega-3 acids. Patients without coeliac disease or other forms of gluten intolerance should not be advised to follow a glutenfree diet. It is possible that lactose intolerance occurs, which should be addressed by patients with hormone regulation problems by taking medication. Nutritional deficiencies, chronic inflammation accompanied by intestinal dysbiosis indicate unhealthy eating habits, including inadequate intake of vegetables, fruit, food that supports the antioxidant potential of plasma and the body. Improvement of these aspects of nutrition improves the nutritional status of patients and supports the therapy of the disease.

\section{REFERENCES}

1. Krysiak R, Szkróbka W, Okopień B. The Effect of Gluten-Free Diet on Thyroid Autoimmunity in Drug-Naïve Women with Hashimoto's Thyroiditis: A Pilot Study. Exp Clin Endocrinol Diabetes. 2018 Jul 30. https://doi.org/10.1055/a-0653-7108.

2. Hiromatsu Y, Satoh H, Amino N. Hashimoto's thyroiditis: history and future outlook. Hormones (Athens, Greece). 2013; 12(1): 12-18.

3. Monaco F. Thyroid Diseases. Taylor and Francis; 2012, p. 78.

4. Pyzik A, Grywalska E, Matyjaszek-Matuszek B, Roliński J. Immune disorders in Hashimoto's thyroiditis: what do we know so far? J Immunol Res. 2015; 2015: 979167. https://doi.org/10.1155/2015/979167.

5. Ott J, Promberger R, Kober F, Neuhold N, Tea M, Huber JC et al. Hashimoto's thyroiditis affects symptom load and quality of life unrelated to hypothyroidism: a prospective case-control study in women undergoing thyroidectomy for benign goiter. Thyroid 2011; 21: 161-167.

6. Wiersinga WM. Clinical Relevance of Environmental Factors in the Pathogenesis of Autoimmune Thyroid Disease. Endocrinol Metab. 2016; 31: 213-22. https://doi.org/10.3803/EnM.2016.31.2.213.

7. Boas M, Feldt-Rasmussen U, Main KM. Thyroid effects of endocrine disrupting chemicals. Mol Cell Endocrinol 2012; 355: 240-148. https:// doi.org/10.1016/j.mce.2011.09.005.

8. Kawicka A, Regulska-Ilow B. [Metabolic disorders and nutritional status in autoimmune thyroid diseases]. Postepy Hig Med Dosw (online) 2015; 69: 80-90 (Polish). https://doi.org/10.5604/17322693.1136383.

9. Lizis-Kolus K. Ocena wpływu niedoboru witaminy D na przebieg choroby Hashimoto u chorych w województwie świętokrzyskim [praca doktorska]. Kraków; Uniwersytet Jagielloński; 2015 (Polish).

10. Virili C, Fallahi P, Antonelli A, Benvenga S, Centanni M. Gut microbiota and Hashimoto's thyroiditis. Rev Endocr Metab Disord. 2018; 19(4): 293-300. https://doi.org/10.1007/s11154-018-9467-y

11. Benvenga S, Guarneri F. Molecular mimicry and autoimmune thyroid disease. Rev Endocr Metab Disord. 2016; 17: 485-498. https://doi. org/10.1007/s11154-016-9363-2.

12. Palm NW, de Zoete MR, Flavell RA. Immune-microbiota interactions in health and disease. Clin Immunol. 2015; 159: 122-127. https://doi. org/10.1016/j.clim.2015.05.014.

13. Liu YZ, Wang YX, Jiang CL. Inflammation: The Common Pathway of Stress-Related Diseases. Front Hum Neurosci. 2017; 11: 316. https:// doi.org/10.3389/fnhum.2017.00316.

14. Nowotny K, Jung T, Höhn A, Weber D, Grune T. Advanced glycation end products and oxidative stress in type 2 diabetes mellitus. Biomolecules. 2015 Mar 16; 5(1):194-222. doi: 10.3390/biom5010194.

15. Aseervatham GS, Sivasuda T, Jeyadevi R, Arul Ananth D. Environmental factors and unhealthy lifestyle influence oxidative stress in humans - an overview. Environ Sci Pollut Res Int. 2013; 20(7): 4356-4369. https:// doi.org/10.1007/s11356-013-1748-0.

16. Uribarri J, del Castillo MD, de la Maza MP, Filip R, Gugliucci A, Luevano-Contreras C, et al. Dietary advanced glycation end products and their role in health and disease. Adv Nutr 2015; 6: 461-473. https:// doi.org/10.3945/an.115.008433.

17. Costantino S, Paneni F, Battista R, Castello L, Capretti G, Chiandotto $S$, et al. Impact of glycemic variability on chromatin remodelling, oxidative stress, and endothelial dysfunction in patients with type 2 diabetes and with target HbAlc levels. Diabetes 2017; 66: 2472-2482. https://doi.org/10.2337/db17-0294. 
18. Pirillo A, Norata GD, Catapano AL. Postprandial lipemia as a cardiometabolic risk factor. Curr Med Res Opin 2014; 30: 1489-1503. https://doi.org/10.1185/03007995.2014.909394.

19. Manna P, Jain SK. Obesity, oxidative stress, adipose tissue dysfunction, and the associated health risks: causes and therapeutic strategies. Metab Syndr Relat Disord. 2015; 13: 423-444. https://doi.org/10.1089/ met.2015.0095.

20. Sarniak A, Lipińska J, Tytman K, Lipińska S. [Endogenous mechanisms of reactive oxygen species (ROS) generation]. Postepy Hig Med. Dosw (online) 2016; 70: 1150-1164 (Polish).

21. Cho BA, Yoo SK, Song YS, Kim SJ, Lee KE, Shong M, et al. Transcriptome network analysis reveals aging-related mitochondrial and proteasomal dysfunction and immune activation in human thyroid. Thyroid 2018; 28: 656-666. https://doi.org/10.1089/thy.2017.0359.

22. Dikic I. Proteasomal and autophagic degradation systems. Annu Rev Biochem. 2017; 86: 193-224. https://doi.org/10.1146/annurevbiochem-061516-044908.

23. Birben E, Sahiner UM, Sackesen C, Erzurum S, Kalayci O. Oxidative Stress and Antioxidant Defense. World Allergy Organ J. 2012; 5(1): 9-19. https://doi.org/10.1097/WOX.0b013e3182439613.

24. Karbownik-Lewińska M, Kokoszko-Bilska A. Oxidative damage to macromolecules in the thyroid - experimental evidence. Thyroid Res. 2012; 5: 25. https://doi.org/10.1186/1756-6614-5-25

25. Reddy VS, Bukke S, Mahato K, Kumar V, Reddy NV, Munikumar M, et al. A meta-analysis of the association of serum ischaemia-modified albumin levels with human hypothyroidism and hyperthyroidism. Biosci Rep 2017; 37: pii: BSR20160268. https://doi.org/10.1042/ BSR20160268

26. Ruggeri RM, Vicchio TM, Cristani M, Certo R, Caccamo D, Alibrandi A, et al. Oxidative stress and advanced glycation end products in Hashimoto's thyroiditis. Thyroid 2016; 26: 504-511. https://doi. org/10.1089/thy.2015.0592

27. Ventura M, Melo M, Carrilho F. Selenium and Thyroid Disease: From Pathophysiology to Treatment. Int J Endocrinol. 2017; 2017: https:// doi.org/1297658. 10.1155/2017/1297658

28. Ates I, Yilmaz FM, Altay M, Yilmaz N, Berker D, Güler S. The relationship between oxidative stress and autoimmunity in Hashimoto's thyroiditis. Eur J Endocrinol 2015; 173: 791-799. https://doi.org/ 10.1530/EJE-15-0617

29. Ascorbate and Glutathione: The Heart of the Redox Hub Christine H. Foyer, Graham NoctorPublished January 2011. doi: https://doi. org/10.1104/pp.110.167569

30. Rostami R, Aghasi MR, Mohammadi A, Nourooz-Zadeh J. Enhanced oxidative stress in Hashimoto's thyroiditis: inter-relationships to biomarkers of thyroid function. Clin Biochem. 2013; 46: 308-312. https://doi.org/10.1016/j.clinbiochem.2012.11.021

31. Nanda N, Bobby Z, Hamide A. Oxidative stress in anti thyroid peroxidase antibody positive hypothyroid patient. Asian J Biochem 2012; 7: 54-58. https://doi.org/10.3923/ajb.2012.54.58

32. Baser H, Can U, Baser S, Yerlikaya FH, Aslan U, Hidayetoglu BT. Assessment of oxidative status and its association with thyroid autoantibodies in patients with euthyroid autoimmune thyroiditis. Endocrine 2015; 48: 916-923. https://doi.org/10.1007/s12020-0140399-3.

33. Perricone C, De Carolis C, Giacomelli R, Greco E, Cipriani P, Ballanti $\mathrm{E}$ et al. Inhibition of the complement system by glutathione: molecular mechanisms and potential therapeutic implications. Int J Immunopathol Pharmacol 2011; 24: 63-68.

34. Zhang Z, Zhang X, Fang X, Niimi M, Huang Y, Piao H, et al. Glutathione inhibits antibody and complement-mediated immunologic cell injury via multiple mechanisms. Redox Biol 2017; 12: 571-581. https://doi.org/ 10.1016/j.redox.2017.03.030

35. Oxidative post-translational modifications and their involvement in the pathogenesis of autoimmune diseases Brent J.Ryan Paul G.Winyard https://doi.org/10.1016/j.redox.2014.05.004

36. Giannakou M, Saltiki K, Mantzou E, Loukari E, Philippou G, Terzidis $\mathrm{K}$, et al. RAGE polymorphism and oxidative stress levels in Hashimoto's thyroiditis. Eur J Clin Invest 2017; 47: 341-347. https://doi.org/10.1111/ eci.12739

37. Giannakou M, Saltiki K, Mantzou E, Loukari E, Philippou G, Terzidis $\mathrm{K}$, et al. The effect of obesity and dietary habits on oxidative stress in Hashimoto's thyroiditis. Endocr Connect 2018; 7: 990-997. https://doi. org/10.1530/EC-18-0272

38. Omeljaniuk WJ, Dziemanowicz M, Naliwajko SK, Bartosiuk E, Markiewicz-Żukowska R, Borawska MH. [Evaluation of the diet of patients with Hashimoto's disease]. Bromat Chem Toksykol 2011; 44: 428-433 (Polish).
39. Pietrych A, Filip R. [Effect of diet on reducing body mass in patients with overweight and obesity]. Probl Hig Epidemiol 2011; 92: 577-579 (Polish).

40. Gibiński M, Sikora M. [Food and non-food applications of betaglucans]. Kraków; Uniwersytet Rolniczy w Krakowie; 2009 (Polish).

41. Chin KY, Ima-Nirwana S, Mohamed IN, Aminuddin A, Johari MH, Ngah WZ. The relationship between thyroid hormones and thyroidstimulating hormone with lipid profile in euthyroid men. Int J Med Sci 2014; 11: 349-355. https://doi.org/10.7150/ijms.7104

42. Zakrzewska E, Zegan M, Michota-Katulska E. [Dietary recommendations in hypothyroidism with coexistence of Hashimoto's disease]. Bromat Chem Toksykol 2015; 18: 117-127 (Polish).

43. Shiqian $\mathrm{Hu}$ and Margaret P. Rayman. Multiple Nutritional Factors and the Risk of Hashimoto's Thyroiditis. Thyroid VOL. 27, NO. 51 May 2017 https://doi.org/10.1089/thy.2016.0635

44. Khatiwada S, Gelal B, Baral N, Lamsal M. Association between iron status and thyroid function in Nepalese children. Thyroid Res. 2016; 9: 2. https://doi.org/10.1186/s13044-016-0031-0

45. Zimmermann MB, Gizak M, Abbott K, Andersson M, Lazarus JH. Iodine deficiency in pregnant women in Europe. Lancet Diabetes Endocrinol 2015; 3(9): 672-674. https://doi.org/10.1016/S22138587(15)00263-6

46. Gietka-Czernel M. [Iodine prophylaxis] 2015; 28: 839-845 (Polish).

47. Stolińska H, Wolańska D. [Nutrients important in hypothyroidism]. Żyw. Czł. i Metabol. 2012; 39: 221-231 (Polish).

48. Szybiński Z. Iodine prophylaxis in the lights of the last recommendation of who on reduction of daily salt intake. Recent Pat Endocr Metab Immune Drug Discov. 2017; 11: 39-42. https://doi.org/10.2174/18722 14811666170608120810

49. Sengupta P. Potential Health Impacts of Hard Water. Int J Prev Med 2013; 4: 866-875.

50. Iodine and thyroid function. Hye Rim Chung Ann Pediatr Endocrinol Metab. 2014 Mar; 19(1): 8-12. Published online 2014 Mar 31. doi: 10.6065/apem.2014.19.1.8

51. Sang Z, Wang PP, Yao Z, Shen J, Halfyard B, Tan L, et al. Exploration of the safe upper level of iodine intake in euthyroid Chinese Adults: a randomized double-blind trial. Am J Clin Nutr 2012; 95: 367-373. https://doi.org/10.3945/ajcn.111.028001

52. Xu C, Wu F, Mao C, Wang X, Zheng T, Bu L, et al. Excess iodine promotes apoptosis of thyroid follicular epithelial cells by inducing autophagy suppression and is associated with Hashimoto thyroiditis disease. J Autoimmun 2016; 75: 50-57. https://doi.org/10.1016/j. jaut.2016.07.008

53. Xu J, Liu XL, Yang XF, Guo HL, Zhao LN, Sun XF. Supplemental selenium alleviates the toxic effects of excessive iodine on thyroid. Biol Trace Elem Res 2011; 141: 110-118. https://doi.org/10.1007/s12011010-8728-8

54. Xue H, Wang W, Li Y, Shan Z, Li Y, Teng X, et al. Selenium upregulates $\mathrm{CD} 4(+) \mathrm{CD} 25(+)$ regulatory $\mathrm{T}$ cells in iodine-induced autoimmune thyroiditis model of NOD.H-2(h4) mice. Endocr J. 2010; 57: 595-601.

55. Duntas LH, Benvenga S. Selenium: an element for life. Endocrine 2015 48: 756-775. https://doi.org/10.1007/s12020-014-0477-6

56. Krysiak R, Okopien B. The effect of levothyroxine and selenomethionine on lymphocyte and monocyte cytokine release in women with Hashimoto's thyroiditis. J Clin Endocrinol Metab 2011; 96: 2206-15. https://doi.org/10.1210/jc.2010-2986

57. Socha K, Dziemianowicz M, Omeljaniuk WJ, Soroczyńska J, Borawska MH. [Dietary habits and the concentration of selenium in serum of patients with Hashimoto disease]. Probl Hig Epidemiol 2012; 93: 824-827 (Polish)

58. Kieliszek M, Błażejak S. Current knowledge on the importance of selenium in food for living organisms: a review. Molecules 2016; 21(5). pii: E609. https://doi.org/10.3390/molecules21050609

59. Kalaras MD, Richie JP, Calcagnotoo A, Beelman RB. Mushrooms: A rich source of the antioxidants ergothioneine and glutathione. Food Chemistry 2017; 233: 429-433. https://doi.org/10.1016/j. foodchem.2017.04.109

60. Liontiris MI, Mazokopakis EE. A concise review of Hashimoto thyroiditis (HT) and the importance of iodine, selenium, vitamin $\mathrm{D}$ and gluten on the autoimmunity and dietary management of HT patients. Points that need more investigation. Hell J Nucl Med. 2017; 20: 51-56. https://doi.org/10.1967/s002449910507

61. Betsy A, Binitha MP, Sarita S. Zinc deficiency associated with hypothyroidism: an overlooked cause of severe alopecia. Int J Trichology 2013; 5: 40-42. https://doi.org/10.4103/0974-7753.114714

62. Wang K, Wei H, Zhang W, Li Z, Ding L, Yu T, et al. Severely low serum magnesium is associated with increased risks of positive anti- 
thyroglobulin antibody and hypothyroidism: A cross-sectional study. Sci Rep 2018; 8: 9904. https://doi.org/10.1038/s41598-018-28362-5

63. Wang J, Lv S, Chen G, Gao C, He J, Zhong H, et al. Meta-analysis of the association between vitamin $\mathrm{D}$ and autoimmune thyroid disease. Nutrients 2015; 7: 2485-98. https://doi.org/10.3390/nu7042485

64. Włochal M, Kucharski MA, Grzymisławski M. The effects of vitamins and trace minerals on chronic autoimmune thyroiditis. Journal of Medical Science 2014; 83: 167-72.

65. K. Vonrad, L. Starka, R. Hampl. Vitamin D and Thyroid Diseases. Physiol. Res. 64 (Suppl. 2): S95-S100, 2015.

66. Markiewicz-Żukowska R, Naliwajko SK, Bartosiuk E, Sawicka E, Omeljaniuk W, Borawska M. [The content of vitamins in diets of patients with Hashimoto disease]. Bromat Chem Toksykol 2011; 44: 539-543 (Polish).

67. Mansournia N, Mansournia MA, Saeedi S, Dehghan J. The association between serum $25 \mathrm{OHD}$ levels and hypothyroid Hashimoto's thyroiditis. J Endocrinol Invest 2014; 37: 473-476. https://doi.org/10.1007/s40618014-0064-y

68. Zhao F, Feng J, Li J, Zhao L, Liu Y, Chen H, et al. Alterations of the Gut Microbiota in Hashimoto's Thyroiditis Patients. Thyroid 2018; 28 : 175-186. https://doi.org/10.1089/thy.2017.0395

69. Peng S, Li C, Wang X, Liu X, Han C, Jin T, et al. Increased Toll-Like Receptors Activity and TLR Ligands in Patients with Autoimmune Thyroid Diseases. Front Immunol. 2016; 7: 578. https://doi.org/10.3389/ fimmu. 2016.00578

70. Luo X, Zheng T, Mao C et, Dong X, Mou X, Xu C, al. Aberrant MRP14 expression in thyroid follicular cells mediates chemokine secretion through the IL-1 $1 /$ MAPK pathway in Hashimoto's thyroiditis. Endocr Connect. 2018; 7: 850-858. https://doi.org/10.1530/EC-18-0019.

71. Durack J, Lynch SV. The gut microbiome: Relationships with disease and opportunities for therapy. J Exp Med. 2019; 216: 20-40. https:// doi.org/10.1084/jem.20180448

72. Sheflin AM, Melby CL, Carbonero F, Weir TL. Linking dietary patterns with gut microbial composition and function. Gut Microbes 2017; 8: 113-129. https://doi.org/10.1080/19490976.2016.1270809

73. Caesar R, Tremaroli V, Kovatcheva-Datchary P, Cani PD, Bäckhed F. Crosstalk between Gut Microbiota and Dietary Lipids Aggravates WAT Inflammation through TLR Signaling. Cell Metab. 2015; 22: 658-68. https://doi.org/10.1016/j.cmet.2015.07.026

74. Mani V, Hollis JH, Gabler NK. Dietary oil composition differentially modulates intestinal endotoxin transport and postprandialendotoxemia. Nutr Metab (Lond) 2013; 10: 6. https://doi.org/10.1186/1743-7075-10-6

75. Jang S, Sun J, Chen P, Lakshman S, Molokin A, Harnly JM, et al. Flavanol-Enriched Cocoa Powder Alters the Intestinal Microbiota, Tissue and Fluid Metabolite Profiles, and Intestinal Gene Expression in Pigs. J Nutr 2016; 146: 673-680. https://doi.org/10.3945/jn.115.222968

76. Cianciosi D, Forbes-Hernandez TY, Afrin S, Gasparrini M, ReboredoRodriguez P, Manna PP, et al. Phenolic Compounds in Honey and Their Associated Health Benefits: A Review. Molecules 2018; 23: pii: E2322. https://doi.org/10.3390/molecules23092322
77. Samarghandian S, Farkhondeh T, Samini F. Honey and Health: A Review of Recent Clinical Research. Pharmacognosy Res. 2017; 9: 121-127. https://doi.org/10.4103/0974-8490.204647

78. Costantini L, Molinari R, Farinon B, Merendino N. Impact of Omega-3 Fatty Acids on the Gut Microbiota. Int J Mol Sci. 2017; 18: E2645. https:// doi.org/10.3390/ijms18122645

79. Mason RP, Sherratt SCR. Omega-3 fatty acid fish oil dietary supplements contain saturated fats and oxidized lipids that may interfere with their intended biological benefits. Biochem Biophys Res Commun 2017; 483: 425-429. https://doi.org/10.1016/j.bbrc.2016.12.127

80. Mori K, Nakagawa Y, Ozaki H. Does the gut microbiota trigger Hashimoto's thyroiditis? Discov Med 2012; 14: 321-326.

81. Genton L, Cani PD, Schrenzel J. Alterations of gut barrier and gut microbiota in food restriction, food deprivation and protein-energy wasting. Clin Nutr 2015; 34: 341-349. https://doi.org/10.1016/j. clnu.2014.10.003

82. Asik M, Gunes F, Binnetoglu E, Eroglu M, Bozkurt N, Sen H, Akbal E, Bakar C, Beyazit Y, Ukinc K. Decrease in TSH levels after lactose restriction in Hashimoto's thyroiditis patients with lactose intolerance. Endocrine. 2014 Jun; 46(2): 279-84. doi:10.1007/s12020-013-0065-1

83. Asik M, Gunes F, Binnetoglu E, Eroglu M, Bozkurt N, Sen H, et al. Decrease in TSH levels after lactose restriction in Hashimoto's thyroiditis patients with lactose intolerance. Endocrine 2014; 46: $279-284$.

84. Ratajczak AR, Moszak M, Grzymisławski M. [Dietary recommendations for hypothyroidism and Hashimoto's disease]. Piel Zdr Publ 2017; 7: 305-311 (Polish). https://doi.org/10.17219/pzp/76716

85. Ozkan C, Yetkin I. Coeliac disease and autoimmune thyroid diseases. Med-Science 2016; 5: 1055-1058.

86. Sharma BR, Joshi AS, Varthakavi P, Chadha MD, Bhagwat NM, Pawal PS. Coeliac autoimmunity in autoimmune thyroid disease is highly prevalent with a questionable impact. Indian J Endocrinol Meta 2016; 20: 97-100. https://doi.org/10.4103/2230-8210.172241

87. Lambert J, Vojdani A. Correlation of Tissue Antibodies and Food Immune Reactivity in Randomly Selected Patients Specimens. J Clin Cell Immunol 2017; 8: 521. https://doi.org/10.4172/2155-9899.1000521

88. Kharrazian D, Herbert M, Vojdani A. Immunological reactivity using monoclonal and polyclonal antibodies of autoimmune thyroid target sites with dietary proteins. J Thyroid Res 2017; 2017: 4354723. https:// doi.org/10.1155/2017/4354723

89. Wawrzeńczyk A, Bartuzi Z. [Cross-reactivity syndromes]. Alergia Astma Immunologia 2018; 23(2): 64-66 (Polish).

90. Vici G, Belli L, Biondi M, Polzonetti V. Gluten free diet and nutrient deficiencies: A review. Clin Nutr. 2016; 35: 1236-1241. https://doi. org/10.1016/j.clnu.2016.05.002

91. Dorota Szostak-Węgierek, Tomasz Bednarczuk The validity of glutenfree diet in Hashimoto's thyroiditis: statement of the Expert Committee of the Section of Medical Dietetics of the Polish Society for Parenteral, Enteral Nutrition and Metabolism (POLSPEN) Postępy Żywienia Klinicznego Nr 2/2018 (47) Tom 14. 